\title{
AN INVESTIGATION OF THE RELATIONSHIP BETWEEN TEST ANXIETY AND ACADEMIC PERFORMANCE IN SECONDARY SCHOOLS IN NYERI DISTRICT, KENYA
}

\author{
G. W. NDIRANGU; J. M. MUOLA; M. R. KITHUKA AND D. K. NASSIUMA
}

\begin{abstract}
The objective of this study was to determine the relationship between test anxiety and academic performance among students in Nyeri district, Kenya. The correlational study design was used. The study was carried out among form four students together with their teachers. The target population was 83,000 students and 600 teachers from the District. Eighty students from four schools and 12 teachers were randomly sampled. Three instruments prepared by the researchers were administered, that is, a Students' Questionnaire, a Teachers' and a Students' Interview Schedules. The results showed that there is a statistically significant difference $(P<0.01, t=-3.736)$ between test anxiety levels before and after examinations. High anxiety is experienced before the examination in all subjects. It was also established that both girls and boys are equally affected by test anxiety. The results showed that teachers do not adequately help students cope with test anxiety. There was no significant relationship ( $r$ $=0.06$ ) between test anxiety and academic performance. It was recommended that a curriculum that is inclusive of strategies of coping with test anxiety be developed.
\end{abstract}

KEY WORDS: test, anxiety, academic performance, coping strategies, examination

\section{INTRODUCTION}

The Kenya National Examination Council (KNEC) which was established by an act of parliament, conduct examinations in Kenya (Agba \& Lopokoiyot, 1992). The KNEC examinations are based on the syllabus prepared by the Kenya Institute of Education (KIE). The examinations have their own inherent limitations. The scores on them are regarded as the sole objective of education and are used to admit students into colleges, universities and as a basis for employment. This makes students develop test anxiety due to the seriousness with which the examination is regarded and perceived.

When individuals are pressurized to make high scores in a test, their anxiety is bound to increase (Deffenbacher, 1978). Goldman
(1971) found that individuals with high levels of anxiety tend to do worse on cognitive tests. Wine (1980) concluded that individuals with high test anxiety worry about not doing as well as they would like to do on a test. Most people find examinations stressful and may focus on expectations of failure and the undesirable consequences of personal inadequacy (Smith, 1982).

According to a report by the Kenya Government task force (GOK, 2001) on student discipline and unrest in secondary schools, the number of tests done as part of continuous assessment are often excessive and cause stress to students. The test related stress may result in cases of indiscipline and poor academic performance. Cases of unrest are reported in schools during the second term as a result of

G. W. Ndirangu,_Egerton University, Laikipia Campus College, P.O. BOX 13855, Nakuru

J. M. Muola, Egerton University, Laikipia Campus College, P.O. BOX 13855, Nakuru

M. R. Kithuka, Egerton University, Laikipia Campus College, P.O. BOX 13855, Nakuru

D. K. Nassiuma, Egerton University, Laikipia Campus College, P.O. BOX 13855, Nakuru 
anxiety associated with district mock examinations (GOK, 2001).

Excessive anxiety may have a detrimental effect on individual performance (Tobias, 1979; Sarason, 1980; Tyron, 1980). Anxiety interferes with normal behaviour and may affect performance in tasks that require competence. It was observed that the performance in the Kenya Certificate of Secondary Examination (KCSE) which is done at the end of the four year secondary education has been consistently low between 1991 and 2002 with a mean score of about 4.9 or $C$ minus in Nyeri District (Nyeri Education Office, 2003). Research has been done on other factors that influence academic performance in Kenya, but there is no research known to the researchers that has attempted to look at the effect of test anxiety on academic performance. In addition, contradicting findings in this area have been reported. Hence, the need to investigate the relationship between test anxiety and academic performance in the district.

\section{Hypotheses \\ It was hypothesized that there is no significant: \\ i. Difference between test anxiety levels in students before and after examinations. \\ ii. Difference in the level of anxiety aroused in students by different subjects \\ iii. Difference between anxiety levels in girls and boys. \\ iv. Relationship between test anxiety and academic performance. \\ v. Relationship between students' strategies of coping with test anxiety and the level of test anxiety}

\section{Literature Review}

In this study, test anxiety is conceived as the hyper-arousal condition that results in physiological, emotional and intellectual changes that prevent the effective use of the previously learned information, while taking an examination. It is composed of "worry" which is a cognitive anxiety related with performance and "emotionality", the arousal of autonomic nervous system in evaluative situations (Morris \& Liebert, 1970).

Although everybody experiences anxiety, only some are impaired by it. Anxiety at moderate levels is necessary for efficient functioning and performance. However, at very high levels it may impair normal functioning and performance in a task. Test anxiety is important in education because it helps student prepare for exams.
Failure experiences among other factors would cause rise in test anxiety (Gaundry \& Spielerger, 1971).

According to the psychodynamic theory, anxiety results from a failure to repress painful memories, impulses or thoughts. Behavioural theories look at it as a reaction to stimuli in the environment. For example, getting conditioned to fear exams since they have come to be associated with failure. Biologically, human beings are genetically predisposed to react differently to anxiety provoking situations (Harris, 1983). Thus, the same situation will arouse different levels of anxiety in different individuals.

It is expected that students' levels of test anxiety will rise during the examination period as compared to other times of the school term. However, a study by Ibrahim (1996) on 125 college students found no significant differences between their levels of stress during the beginning of term, middle of the term and prior to end term examinations. This implied that stress is not influenced by the anticipation of an examination. This was attributed to inclusion of continuous assessment test marks (40\%) in the final examination, being prepared for the examination among other factors. This finding is contrary to earlier findings which have shown that examinations increase anxiety (Dussek, 1980; Philips \& Endler, 1983).

Anxiety levels in students in regard to different subjects may be different. Some subjects may elicit higher levels of anxiety than others. Subjects that are perceived by students to be difficult such as Mathematics will trigger anxiety in the individual student and consequently interfere with their performance. Keeves (1985) indicates that girls are higher in measures of fear and that this fear is higher for quantitative studies considered a male preserve than in language studies. Zoller and Bencham (1990) found the anxiety of females to be higher than that of male students in science examinations. A study on the relationship between test anxiety and academic performance in 4,000 undergraduate and 1,414 graduate students found both female undergraduates and graduate students to have significantly higher test anxiety than male undergraduates and graduate students (Chapell, Blanding, Silvestein, Takahashi, Newman, Gubi, and McCain, (2005). No significant gender differences $(p=.109 F$ $=2.68$ ) were found on test anxiety in a study of a sample of elementary children in Florida. However, females were found to be slightly more anxious than males at different grade levels 
(Soffer, 2008). These inconclusive findings need further verification through research.

Individuals with low test anxiety do not worry and are able to concentrate on their test performance (Wine, 1980; Drummond, 1996). Therefore, they are likely to perform better than those with high levels of anxiety. According to Woolfork (1995), students do poorly because they are anxious and their poor performance increases their anxiety. Low and moderate levels of anxiety have been associated with significantly high test scores (Cassady \& Johnson, 2002). A study on the relationship between test anxiety and academic performance in 4,000 undergraduate and 1,414 graduate students found a significant but small inverse relationship between test anxiety and grade point average (GPA) in both groups. Low-test-anxious undergraduates averaged a $\mathrm{B}+$, whereas hightest-anxious students averaged a B (Chapell et al., 2005). Other studies have reported similar findings (Gabel, \& Sherwood, 1983; Hong, 1999).

A task force (GOK, 2001) on student indiscipline and unrest in Kenyan schools linked school unrest to stress and anxiety emanating from excessive continuous assessment and mock examinations. Good test taking skills, improved student knowledge base, problem solving skills, ability to manage time effectively, good study skills, following instructions among other things serve to minimize anxiety during examinations (Markel, 1981; Whitman, 1986; Mann, Suiter, \& McClung, 1987; Drummond, 1996).

\section{METHODOLOGY \\ Research Design}

The study used mainly the correlational comparative ex-post facto research design to determine whether test anxiety among students vary with time (i.e., before or after examination), subject area, gender and test anxiety coping strategy. The relationship between test anxiety and academic performance was also determined. The researchers did not have direct control of independent variables and they were taken as they were in a natural setting, hence the suitability of the design adopted.
Participants

Two administrative divisions, Tetu and Mukurweini were randomly selected to take part in this study. Two girls' and two boys' provincial schools were selected from the five provincial schools in the two divisions which has a total of 39 public schools. This kind of selection ensured control of gender bias and also meant that the respondents were more or less of the same ability since provincial schools admit students of more or less the same qualifications. Twenty students were randomly selected from each school to get a sample of 80 . The simple random method was used to select 12 teachers from a population of 600 teachers in the schools. This small number of teachers was used to provide additional information on some of the strategies used by students to reduce text anxiety.

\section{Instrumentation}

The Students' Questionnaire and Interview Schedules for students and teachers were used. A reliability coefficient of 0.79 was obtained for the Students' Questionnaire which mainly measured test anxiety. The Interview Schedules involved collection of data through direct verbal interaction with the respondents. They yielded qualitative information from respondents about academic performance, unrest and test anxiety reduction strategies.

\section{RESULTS AND DISCUSSIONS}

The results indicated that, $68.1 \%$ of the students experienced test anxiety before taking examinations while $31.9 \%$ did not. This is in agreement with the view that anxious students see themselves as ineffective and inadequate to handle the examination (Smith, 1982). The study showed that $89.4 \%$ felt uneasy before getting their test papers back as compared to $10.6 \%$ who did not. The results also indicated that $27.7 \%$ of the students felt depressed after taking a test as compared to $72.3 \%$ who did not. This is because as soon as an examination is over, students feel relaxed and anxiety levels are low. Table 1 shows the students' levels of anxiety before and after taking an examination. 
Table 1: Test anxiety before and after examinations

\begin{tabular}{lccccc} 
State of anxiety & \multicolumn{2}{l}{$\begin{array}{l}\text { Before } \\
\text { Frequency }\end{array}$} & \multicolumn{2}{c}{ Percentage } & Frequency Percentage \\
& 54 & 68.1 & 22 & 27.7 \\
\hline Anxious & 26 & 31.9 & 58 & 72.3 \\
\hline Not anxious & 80 & 100 & 80 & 100 \\
\hline Total & &
\end{tabular}

A t-test showed that there is a statistically significant difference $(P<0.01 t=-3.736)$ between test anxiety levels among students before and after examinations as shown in table 2.

Table 2: A t-test analysis for difference between test anxiety before and after examination

\begin{tabular}{lcccccc}
\hline Test anxiety & $\mathbf{N}$ & Mean & $\begin{array}{l}\text { Mean } \\
\text { difference }\end{array}$ & t-value & df & Sig.( 2 tailed) \\
\hline Before & 54 & 4.158 & -0.404 & -3.736 & 46 & 0.001 \\
After & 22 & 3.754 & & & & \\
\hline
\end{tabular}

The results are in agreement with earlier findings (Dussek, 1980; Philips \& Endler, 1983) but contrary to others (Ibrahim, 1996). An examination usually elicits test anxiety and that is why it is higher before one takes it. Increased anxiety has also been reported before the onset of an examination (Gronlund, 1965).
The researchers hypothesized that there is no significant difference between the levels of anxiety aroused in different students by different subjects. The results showed that different clusters of subjects elicited different levels of anxiety as illustrated in table 3 .

Table 3: Level of anxiety elicited by different subject clusters

\begin{tabular}{lcc}
\hline Subject & Frequency & Percentage \\
\hline Mathematics & 34 & 42 \\
Sciences & 25 & 32 \\
Languages & 9 & 11 \\
Technical subjects & 7 & 9 \\
Humanities & 5 & 6 \\
\hline Total & $\mathbf{8 0}$ & $\mathbf{1 0 0}$ \\
\hline
\end{tabular}

The chi-square test for homogeneity showed that there is a statistically significant difference $(P<0.01)$ between the levels of anxiety aroused by different subjects. Thus, it was evident that some subjects elicit higher levels of test anxiety than others. The results are consistent with previous studies that indicate that maximum performance tests like problem solving, situation and critical thinking exercises tend to cause high anxiety in test takers (Keeves, 1985;
Zoller \& Bencham, 1990; Zeider \& Most, 1992;). Mathematics and sciences require critical thinking.

The third hypothesis stated that there is no significant difference between test anxiety levels in girls and boys. The results of the Wilcoxon signed rank sum-test (table 4) indicated that there is no significant difference $(P>0.5, F=$ 0.445 ) between test anxiety levels in girls and boys. 
Table 4: Wilcoxon signed rank sum-test showing test anxiety levels in girls and boys

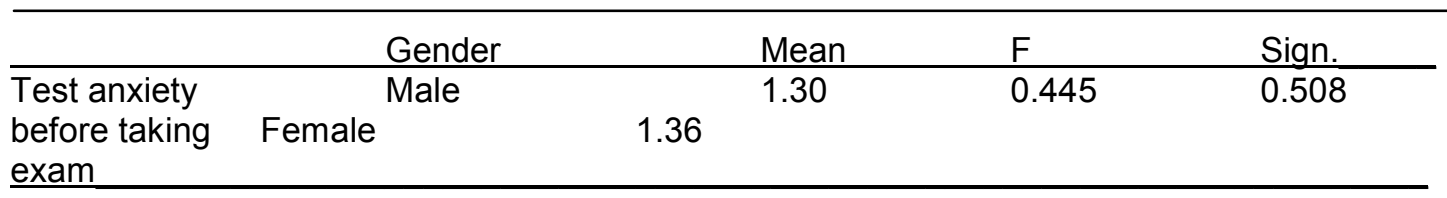

The results contradict earlier findings that showed that girls experience higher levels of anxiety than boys (Keeves, 1985; Chapell et al., 2005; Soffer, 2008). This could be explained by the fact that everybody fears an examination despite their gender and that every one would like to do well. This fear may equally increase anxiety in both male and female students. Students who are not adequately prepared for a test and care about doing well are likely to experience test anxiety. This can apply to both boys and girls.

The fourth hypothesis stated that there is no significant relationship between test anxiety and academic performance. The Spearman's correlation coefficient test showed that there is no significant relationship $(r=0.06)$ between testy anxiety and academic performance. This findings was in disagreement with previous studies which have shown that high test anxiety affects academic performance (Gabel, \& Sherwood, 1983; Convington \& Omelich, 1987; Ibrahim, 1996; Hong, 1999; Chapell et al., 2005 ;). Excessive anxiety has a detrimental effect on individual's performance (Sarason, 1995). The results led to the conclusion that academic performance depends on other factors like intelligence, school facilities, and discipline and not so much on test anxiety. There is need for more studies before concluding with finality that high test anxiety results to low academic grades.

In the Students' Interview Schedules, both students and teachers identified many other factors which they thought affect academic performance. These include peer pressure; attitudes towards examinations, teachers and subjects; study skills; discipline; drug abuse; personal and family problems; facilities; and poor time management among other factors.

The fifth hypothesis stated that there is no significant relationship between levels of test anxiety and coping strategies. Results from the Spearman's Rank Correlation revealed that there is an inverse relationship $(r=-0.014, P=0.928)$ that is not significant between test anxiety and coping strategies. This implies that an increase in coping strategies will reduce test anxiety. Though these findings are not significant at the 0.05 alpha level, they are in agreement with other studies that have shown that coping strategies greatly help in the reduction of test anxiety. Thus, there is need to take such measures seriously in order to improve on test wiseness of students (Drummond, 1996; Cronbach, 1970; Whitman, 1986; Mann et al., 1987).

Some of the strategies that were identified as useful in helping students to reduce test anxiety were:

- Helping students with effective techniques in preparing for examinations

- $\quad$ Provision of guide books

- Conducting class sessions on how to take a test

- Establishment of an environment that is relaxed and stress free

Counselling before examinations

Resting before examinations

Application of relaxation techniques before examinations

\section{CONCLUSION}

The following conclusions were made from the study:

i Students experience high test anxiety before they sit their examinations which can be detrimental to their academic performance.

ii Some subjects elicit more anxiety than others. It is therefore important to focus on reducing test anxiety in those subjects.

iii Both boys and girls are equally affected by test anxiety. Therefore, anxiety reduction strategies should target both.

iv Test anxiety may not be one of the factors that contribute significantly to poor academic performance.

v Anxiety coping strategies are not appropriately used to minimize test 
anxiety among students. If appropriately used these strategies can greatly reduce test anxiety among students.

\section{RECOMMENDATIONS}

The following recommendations were made:

i. It is essential to develop a curriculum that is inclusive of strategies of coping with test anxiety and also develop guidebooks to help students deal with test anxiety.

ii. The misconception that some subjects are more important than others should not be there, but all subjects should be treated with equal significance. Students should be counseled so that they do not develop a notion that some subjects are more difficult and important than others.

iii. Teachers should be motivated so that they may assist students on test taking skills.

iv. Schools should offer the same and equal opportunities to both boys and girls. The society needs to change the socialization process that regards girls as the weaker sex and empower girls the same way it empowers boys.

v. Teachers should develop specific relaxation techniques that best suit their particular students.

vi. Students should seek counseling before doing examinations so as to increase their confidence. They should also have adequate rest before examinations and avoid last minute rush revision.

vii. There is need for further research in this area since contradicting findings have been reported.

\section{REFERENCES}

Agba, C. and Lokopoiyot, M., 1992. Implementation and curriculum reforms: The teaching of Agriculture under the 84-4 programme in secondary schools in Kenya. Egerton University. Unpublished document.

Chapell, M. S.; Blanding, Z. B.; Silvestein, M.E.; Takahashi, M. N. B.; Newman, B. Gubi, A. and McCain, N., $2005 . \quad$ Test anxiety and academic performance in undergraduate and graduate students. Journal of Educational psychology, 97 (2): 268-274.
Cronbach, L., 1970. Essentials of Psychological Testing. New York: Harper and Row Publishers.

Deffenbacher, R., 1978. Worry, emotionality and task generated interference in test anxiety: An empirical test of attentional theory. Journal of Educational Psychology, 70, 248-254.

Drummond, R., 1996. Appraisal Procedures for counselors and helping professionals. New Jersey: Prentice Hall.

Gabel, D.L. and Sherwood R.D., 1983. "Facilitating problem solving in high school chemistry". Journal of Research in Science Teaching, 20(2): 163-177.

Gaundry, E. and Spielberger, C., 1971. Anxiety and educational achievement. Sydney: Wiley and Sons Ltd

Goldman, L., 1971. Using tests in counseling. Pacific Paslisades: Good Year.

Government of Kenya, 2003. Nyeri District KSCE results analysis. Nyeri: Nyeri Disftrict Education Office.

Government of Kenya, 2003. Education in Kenya. Nairobi: Ministry of Education, Science and Technology.

Greenberg, J., 1983. Comprehensive stress management. Dubuque: Brown Company Publisher.

Gronlund, N., 1965. Measurement and evaluation in teaching. London: Macmillan Publishing Company.

Harris, E. L., 1983. Family study of agoraphobia report of a pilot study. Archives of General Psychiatry, 40, 1061-1064.

Hong, E., 1999. "Effects of gender, math ability, trait test anxiety, statistics course anxiety, statistics achievement and perceived test difficulty on state test anxiety". The Annual Meeting of the American Educational Research Association, Montreal, Canada, April 1923. 
Ibrahim, I. I., 1996. Changes in level of anxiety and academic performance of college students. Retrieved February 23, 2009 from http://www.google. co.ke/search?hl=en\&q=kwara+state+coll ege+of+education+ibrahim+anxiety+\&btn $\mathrm{G}=$ Google+Search

Keeves, J., 1972. Educational environment and student achievement. Stolkholm: Almquist and Wiksell Publishers

Keeves, J., 1985. Sex differences in ability and achievement. The International Encyclopedia of Educational Research and Studies. Oxford: Pergamon Press.

Maddaus, F., 1991. The effects of improved test on students: Implications for national examination system. Bloomington: Phi Delta Kappan, Inc.

Mann, G., Suiter, P. and McLung, R., 1987. Handbook in diagnostic perspective teaching. Boston: Allyn and Bacon.

Markel, G., 1981. Improving test taking skills of learning disabled adolescents. Academic Therapy, 16 (3): 333-342.

Maxmen, J., 1966. Essentials of Psychology. London: W. W. Norton and Company.

Morris, L.W. and Liebert, R. M., 1970." Relationship of cognitive and emotional components of test anxiety to physiological arousal and academic performance". Journal of Consulting and Clinical Psychology, 35(3): 332-337.

Nyeri Education Office, 2003. KCSE results analysis. Nyeri.

Republic of Kenya, 2001. Report of the task force on students discipline and unrest in secondary schools. Nairobi: Ministry of Education, Science and Technology.
Sarason, I., 1980. Test anxiety: Theory, research and application. Hillsdale, Erlbaum.

Smith, R., 1982. Psychology: The frontiers of behaviour. New York: Harper and Row Publishers.

Tobias, S., 1979. Anxietyt research in educational psychology. Journal of Educational Psychology, 71, 573-582.

Tyron, G., 1980. The measurement and treatment of test anxiety. Educational Research Review, 50, 343-372.

Whitman, N., Wyne, H. and Gall, M., 1986. Influence on testing and test results. Palo Alto: Consulting Psychologist Press.

Wilson, S. B., 1973. Self-esteem and test anxiety in Black Inner-City Junior High Youngster. Dissertation Abstracts International, 35, 734A.

Soffer, M. E., 2008. Elementary students' test anxiety in relation to the Florida Comprehensive Assessment Test (FCAT). Retrieved February 23, 2009 from

http://etd.lib.fsu.edu/theses/available/etd06092008-111004/ unrestricted/SofferMThesis.pdf.

Wine, J., 1980. Cognitive attentional theory of anxiety. Hillsdale: Erlbaum.

Woolfork, A., 1995. Educational Psychology. Boston: Allyn and Bacon

Zeider, M. and Most, R., 1992. Psychological testing: An Inside View. Palo Alto: Consulting Psychologist Press.

Zoller, L. and Bencham, D., 1990. Gender differences in exam type, preferences, test anxiety and academic achievement in college science education. New York: John Wiley and Sons. 
